\title{
The Impact of Residential and Non-Residential Demand on Location-Allocation Decision-Making: A Case Study of Modelling Suitable Locations for EMS in Leicester and Leicestershire, England UK
}

\author{
Emeka Chukwusa1, Alexis Comber² \\ ${ }^{1}$ School of Geography, Geology and the Environment, University of Leicester, Leicester, UK \\ ${ }^{2}$ School of Geography, Leeds Institute for Data Analytics, University of Leeds, Leeds, UK \\ Email: emechukwusa@yahoo.com, a.comber@leed.ac.uk
}

How to cite this paper: Chukwusa, E. and Comber, A. (2018) The Impact of Residential and Non-Residential Demand on Location-Allocation Decision-Making: A Case Study of Modelling Suitable Locations for EMS in Leicester and Leicestershire, England UK. Journal of Geographic Information System, 10, 381-397.

https://doi.org/10.4236/jgis.2018.104020

Received: June 5, 2018

Accepted: August 11, 2018

Published: August 14, 2018

Copyright $\odot 2018$ by authors and Scientific Research Publishing Inc. This work is licensed under the Creative Commons Attribution International License (CC BY 4.0).

http://creativecommons.org/licenses/by/4.0/

\begin{abstract}
The research examines the impact of residential and non-residential demand on facility location planning by comparing results from two location models: travel-to-work (TTW) and Residential model. The TTW model considers short-term changes in the state of the population due to travel-to-work (non-residential demand). By contrast, the Residential model uses a static snap-shot of the population based on official census estimates (residential demand). Comparison of both models was based on a case study of Emergency Medical Services (EMS) location-allocation planning problem in Leicester and Leicestershire, England, UK. Results showed that the using a static residential demand surface to plan EMS locations overestimates actual demand coverage, compared to a non-residential demand surface. Differences in location-allocation results between the models underscore the importance of accounting for temporal changes in the state of the population when planning locations for health service facilities. The findings of the study have implications for siting of EMS, designing, and planning of EMS service catchments and allocation of prospective demand to EMS sites. The study concludes that consideration of temporal changes in the state of the population is important for reliable and efficient location-allocation planning.
\end{abstract}

\section{Keywords}

Location-Allocation Planning, GIS, Temporal Dynamics, Supply and Demands 


\section{Introduction}

Facility location planning methods have been used to derive optimal locations for service facilities. Notable applications include optimising locations for blood banks [1], fire engines [2], recycling centres [3] [4] and schools [5]. Many studies to date, use population data derived from official census estimates as demand inputs into location planning models, which is based on residential demand or static nighttime population, referred hereafter as "residential demand". The use of residential demand means that facilities are located relative to where people live or reside rather than where they are during the day. In addition, few studies that have incorporated non-residential demand into location planning models often use geographies or spatial units designed for static nighttime population (e.g. Output Area geographies (OAs) used in the UK) to describe non-residential demand, instead of an appropriate non-residential geography (e.g. Workplace Zones).

The current study explores the impact of residential and non-residential demand on facility location planning, by comparing a model that uses static demand (residential model) with that which incorporates non-residential demand (TTW model). The rest of this paper is structured as follows: Section 2, provides a background review of the use of location models in the context of public health. Section 3, describes the methods, study areas, and algorithm used to solve the location problem. Section 4, presents the results of the models. Section 5, discusses the findings and suggests some future research areas before some concluding remark in Section 6.

\section{Background}

Facility location planning is a critical element for making strategic location decisions [6]. The goal is to identify suitable locations for service facilities, referred to as "Supply", such that they are efficiently located to serve a spatially distributed user population known as "Demand". Location planners use mathematical formulations known as "Location models" to derive optimal location for supply locations. Examples of location models are the P-median model [7], Maximal covering location problem [8] and Set covering location models [9].

Location models have long been used to address location planning problems. Early attempts to solve location problems can be traced to the works of Alfred Weber in 1909. Weber demonstrated his idea with a triangle popularly known as the "Weberian triangle" [10]. Weber's technique involved optimising the location of a factory by minimising the cost of moving raw materials under certain simplifying assumptions.

Since the inception of location models, there are many applications in the context of public health. Example applications include testing alternative location planning scenarios for primary health care [11]; identification of the suitability of locations for specialist health care services [12] [13]. Other studies have applied location models by considering the hierarchical structure of healthcare systems. Examples include studies by Mitropoulos and colleagues, who proposed 
a bi-objective within a hierarchical framework for the reallocation of health services in Greece [14]. Their model takes into account the successively inclusive hierarchy inherent in health systems as well as patients' patronage. Locations models have also been used to optimise locations for mobile health facilities such as blood banks [15] [16] or EMS [17] [18]. Khodaparasti and colleagues developed a multi-period location problem to plan the location of nursing home in Shiraz, city Iran [19].

A considerable amount of early works from the Operations research literature and Management sciences have developed location models that incorporated temporally dynamic demand [20]-[25]. However, models have been tested with hypothetically generated demand datasets that do not reflect real dynamic or non-residential demand. In addition, several recent studies have demonstrated the importance of incorporating temporal dynamic demand in location planning problems in the context of risk assessment. Examples include studies by Sleeter and Woods [26], who applied dasymetric mapping together with records from the employee database to identify populations at-risk in the likely event of a tsunami in the coastal areas of Oregon. Kobayashi and Colleagues [27] applied Tobler's Pycnophylactic interpolation [28] to model 24 hourly population surfaces for the dynamic visualisation of population at-risk from a bomb attack and chemical plume. Ahola and Colleagues [29] developed a spatio-temporal population model using workplace datasets to improve damage and risk assessment in the event of a bomb attack. Leung and Colleagues [30] developed a gridded population surface model that includes more temporal scales other than nighttime and daytime population. Martin and Colleagues [31] proposed a method for building time specific population distribution from secondary data sources by taking into account the time profile of the population at different times. Smith and Colleagues [32] applied a similar approach to model temporal population and explore time-specific exposure to flooding. In addition, others have applied location models in the context of large-scale natural hazards such as earthquake [33].

In summary, many public health services research studies demonstrated the viability of location models in solving health services location planning. However, an obvious limitation in their application is the misconception that demands or population that depend on health services are static. The assumption of static demand is contrary to real life circumstances, where everyday activities such as school trips, journey-to-work, leisure parks or shopping malls; continuously influence patterns and distribution of demand at various times of the day. Models that incorporate or represent such spatial processes could result in better decisions about the number of EMS vehicles to deploy, their optimal locations and the size of catchment areas associated with each facility. Moreover, studies from operations research have incorporated temporal dynamic demands but these have only been exemplified using hypothetically generated demand data. This is perhaps due to the lack of temporally disaggregated demand data. The present study exploits the availability of the 2011 travel-to-work date and Workplace Zones (WZs) to formulate the TTW model. The study then examined the impact 
of residential and non-residential on EMS by comparing results generated from the TTW to the Residential models based on case study of EMS location planning problem in Leicester and Leicestershire.

\section{Methods}

\subsection{Overview}

This study explores the impact of residential and non-residential demand on EMS location-allocation planning by comparing a TTW and Residential model. The differences between the models are evaluated in terms of the locations identified, catchment area of identified location, the proportion of demand allocated to each location, mean response times within catchment areas and persons-weighted distance.

\subsection{Study Area}

Leicestershire and Leicester are situated in England, UK. Leicestershire is centrally located and share boundaries with Derbyshire, Warwickshire, Northamptonshire, and Rutland. Leicestershire comprises of the districts of Blaby, Charnwood, Hinckley \& Bosworth, Melton, North West Leicestershire, and Oadby \& Wigston $(\mathrm{O} \& \mathrm{~W})$. According to recent census estimates Leicestershire and Leicester have a population of 650,489 and 329,839 respectively (ONS, 2013). Figure 1 shows the map of the study area.

\subsection{Modelling Residential and Non-Residential Demand}

Demand weights used in the location models comprised of residential and non-residential demands. In the context of this study, the residential demand comprised of the usual resident population derived from the 2011 population census estimates. Non-residential demand consists of the working population in each WZs derived from Census Special Workplace Statistics [34] [35]. The non-residential demand was modelled from travel-to-work data. Travel-to-work data was downloaded from NOMIS, a web-based database of labour market statistics (https://www.nomisweb.co.uk/census/2011/origin_destination). Travel-to-work data consists of an origin and destination matrix, showing the temporary flow of people from their residence (origins) to their workplaces (destinations) in WZs. Non-residential demand was generated from the travel-to-work matrix by adding the total number of commuting inflow into WZs, as shown in Equation (1) and Table 1.

$$
\text { Non-residential demand }=\sum_{j} C_{i j}
$$

In Equation (1), $C$ denotes the number of commuters, commuting from a given residential $\mathrm{OA}(i)$ to a destination $\mathrm{WZ}(j)$.

\subsection{EMS Location-Allocation Modelling, Model Building and Algorithm}

TTW and the Residential model was formulated following the framework of the 


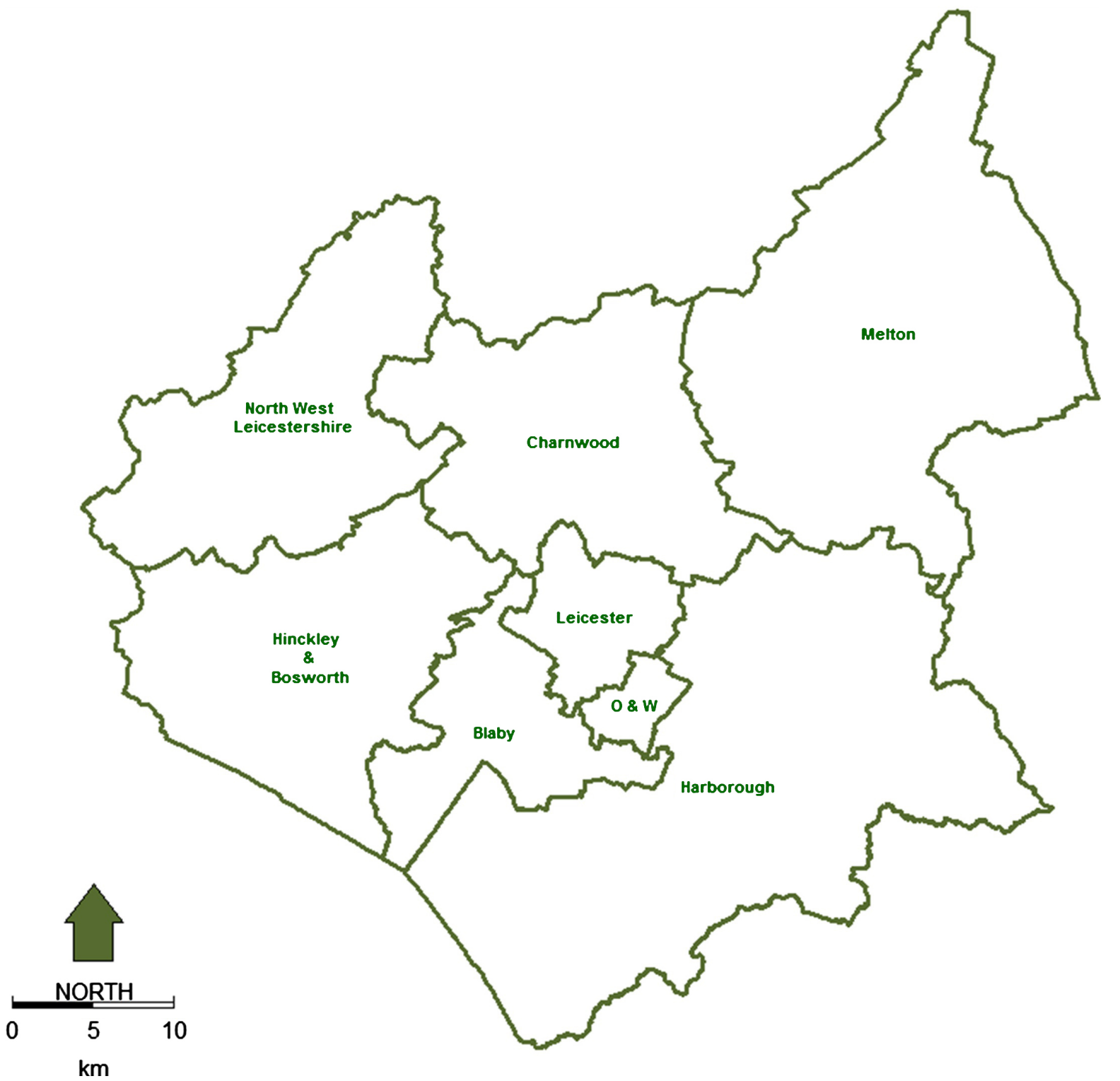

Figure 1. Map of study area. Contains National Statistics data @Crown copyright and database right 2014. Contains Ordnance Survey data @Crown copyright and database right 2014.

Table 1. Matrix of flow between output areas and workplace zones.

\begin{tabular}{|c|c|c|c|c|c|}
\hline & & & \multicolumn{3}{|c|}{ Destination } \\
\hline & & & \multicolumn{3}{|c|}{ (Workplace Zones) } \\
\hline & & & $\mathrm{WZ}_{j}$ & $\mathrm{wZ}_{j}$ & WZ, \\
\hline \multirow{3}{*}{ 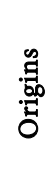 } & \multirow{3}{*}{ 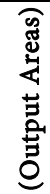 } & $\mathrm{OA}_{i}$ & $C_{i j}$ & $C_{i j}$ & $C_{i j}$ \\
\hline & & $\mathrm{OA}_{i}$ & $C_{i j}$ & $C_{i j}$ & $C_{i j}$ \\
\hline & & $\mathrm{OA}_{i}$ & $C_{i j}$ & $C_{i j}$ & $C_{i j}$ \\
\hline & & & $\sum C_{i j}$ & $\sum C_{i j}$ & $\sum C_{i j}$ \\
\hline
\end{tabular}


P-median model [7]. The objective of both models was to minimise the aggregate travel time between demand points (either non-residential demand or residential demand) and candidate EMS locations. The P-median model was used because its objective conforms to EMS dispatch policy in the UK, i.e. ambulance or paramedics are usually dispatched from the nearest station to the point of emergency call. The P-median model was first formulated by Hakimi, was subsequently transformed into an integer-programming model [36], as shown in Equation (2).

$$
\text { minimise } z=\sum_{i}^{m} \sum_{j}^{n} a_{i} d_{i j} x_{i j}
$$

From Equation (2), $i$ represents the index of demand locations $(i, \cdots, m)$ and $j$ is the index of supply or candidate locations $(j, \cdots, n), a_{i}$ represents the demand weight at demand location $i$. Unlike previous studies, where the same number of origins were used to denote residential and model non-residential demand, this study used different demand weights and number of origins to model residential and working population. As a result, $i$ in Equation (2) corresponds to either non-residential or residential-demand. The parameter $d_{i j}$ is the nearest distance from demand location $i$ to supply location $j$. The parameter $x_{i j}$ is an allocation decision variable, with a binary value of 0 or 1 . The value of $x_{i j}$ is equals 1 , if demand at location $i$, is served by a supply $j$ and 0 if otherwise. Additional constraints and decision variables associated with the P-median model, include the assignment of demands only to selected supply locations and restricting demand allocations to only optimal supply locations. The weighted distance is a component of the objective function of the P-median model. It is denoted by the parameter $\mathrm{a}_{i} \times \mathrm{d}_{i j}$ (Equation (2)).

The P-median model given in Equation (2), is non-deterministic polynomial time hard [37]. This means that it is difficult to solve in polynomial time. For example, choosing a subset of 21 locations from a set of 2050 candidate locations, to allocate to demand in $897 \mathrm{WZs}$ and 3054 OAs requires a very large solution search space of 2050!/21! (2050 - 21)! (Approximately 6.220846e + 49). Deriving solution for this type of problem using total enumeration or brute force is computationally difficult. Many heuristic techniques have been developed in the literature to solve the P-median problem. Some commonly used methods include the Teitz and Bart heuristic [38], Simulated annealing [39], Tabu search [40], Neural model [41] and Genetic algorithm [42]. Although, many of these procedures can derive solutions to the problem rapidly, however their optimality can by no means be guaranteed.

This study used the Grouping Genetic Algorithm (GGA), developed by Comber and colleagues [43] to solve the P-median model. The GGA is a variant of the classic Genetic algorithm, developed to handle subset selection problem. It has been successfully tested on location problems that involve the selection of subsets or groups from a set of location choices. For example, ambulance loca- 
tion planning in Japan [18] and post office site optimisation in Leicestershire [44].

The GGA was implemented in R statistical package (http://www.r-project.org/). The GGA usually runs for a number of predetermined cycles or iterations, until a stopping criterion is reached. After testing the algorithm for several runs a stopping criterion of 50,000 iterations was selected. The P-median formulation, in Equation (2) was used as fitness function to evaluate the quality of chosen locations. The results derived from the application of the GGA are presented in the next section.

\section{Results}

The GGA was parameterised to identify 21 optimal EMS sites. Figure 2(a) and Figure 2(b) show locations identified by TTW and Residential model respectively. Each map indicates the optimal locations for EMS (denoted as red ring) summarised over counts of residential (Figure 2(a)) and non-residential demand (Figure 2(b)). Locations that were identically selected by both models are denoted as red dots.

The results show that of the 21 locations selected by both models, 16 locations were different. In terms of spatial distribution, locations identified by both models are clustered around areas of high demand (i.e. over 1200 persons).

The models were further compared based on the proportion of demand allocated to respective selected locations, catchment areas of selected locations (i.e. service areas) and mean response time within catchment areas. Mean response time was based on the average drive time from selected locations to demand points within catchment areas. Mean response time within catchment areas are represented with hatch lines. The pattern of hatches reflects the mean response time to selected optimal site. Closer and denser hatch lines represent faster mean response time (Figure 3(a) and Figure 3(b)).

Figure 3(a) and Figure 3(b), compare the result of demand allocations and catchments areas for the TTW and Residential models, respectively.

The sizes of the proportional circles displayed on the maps, are weighted by the sizes of the demand allocations to optimal EMS sites identified by the models. The results (Figure 3(a) and Figure 3(b)) show clear differences between the models, in terms of the proportion of demand allocated to each EMS location and the sizes of catchment areas. Proportions of demand allocated to optimal EMS sites derived by the TTW model (Figure 3(a)) are smaller compared to the Residential model (Figure 3(b)). The sizes of catchment areas of the locations identified by the models are different. Mean response times based on the TTW model are faster, compared to the Residential model. For instance, catchment areas modelled with the TTW model have mean response time zones of less than 2 minutes, compared to the Residential model.

Table 2, summarises the percentage of demand covered by EMS, within each 


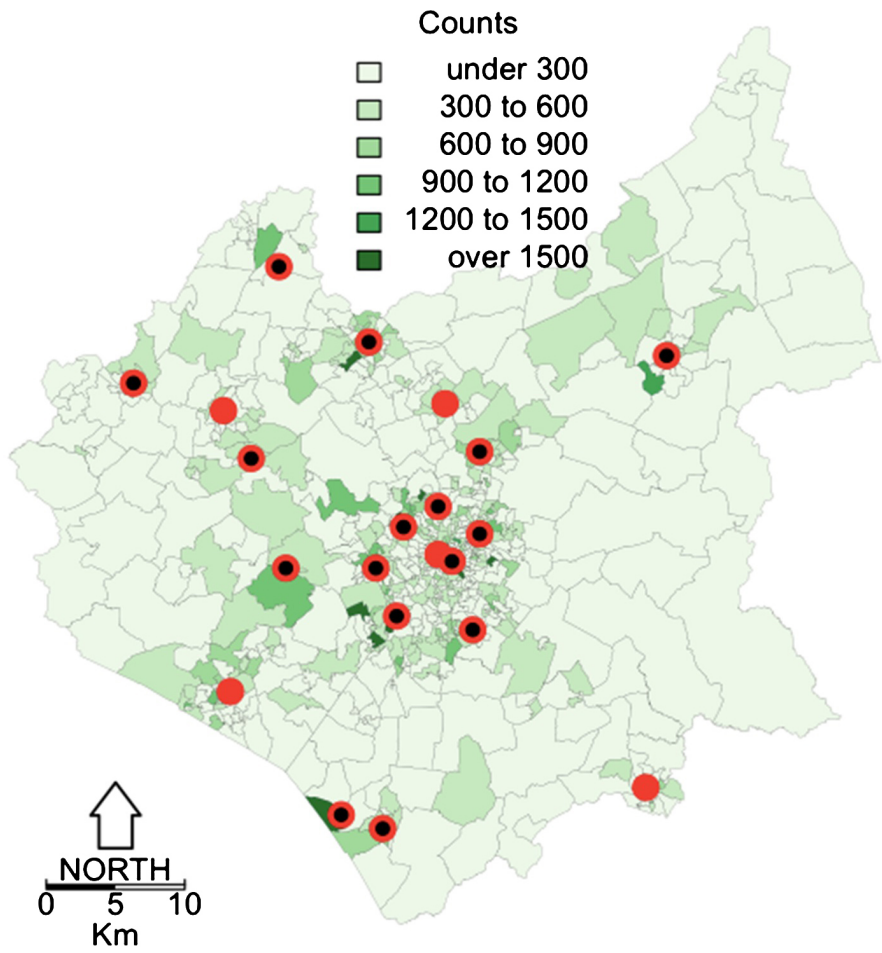

(a)

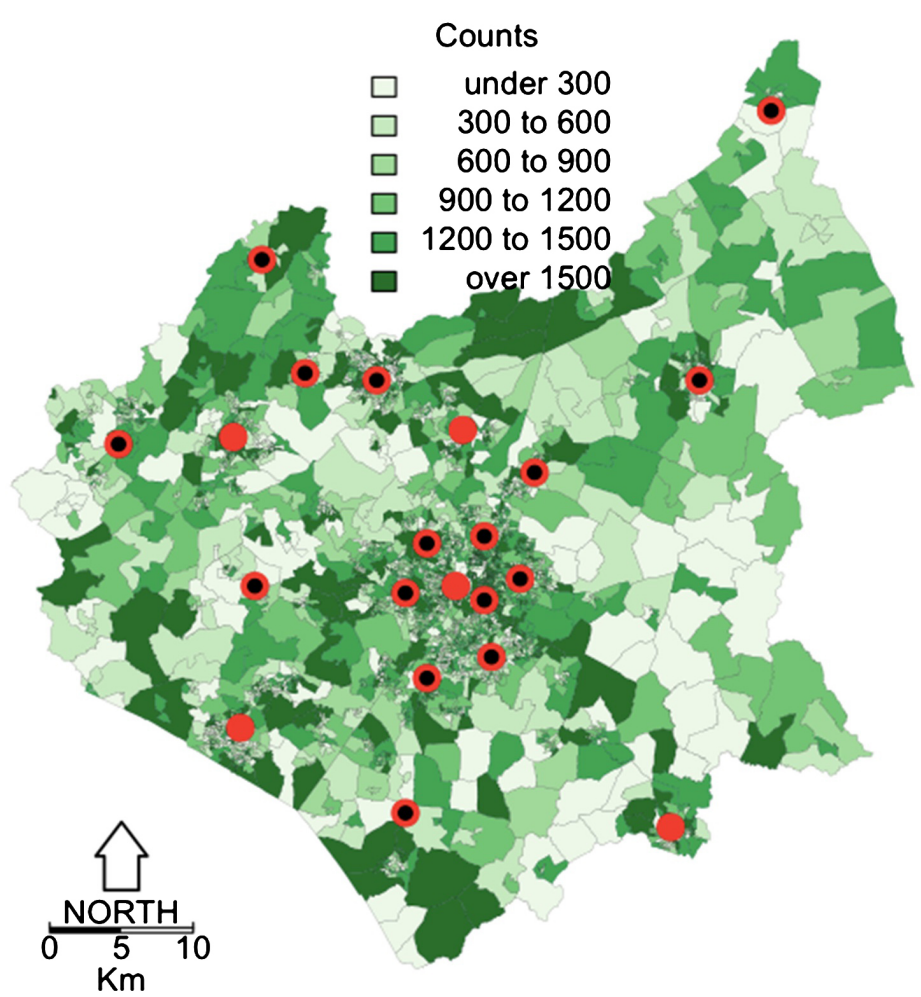

(b)

Figure 2. (a) Optimal EMS location identified by the TTW model. (b) Optimal EMS location identified by the Residential model. Contains National Statistics data (C) Crown copyright and database right 2014. Contains Ordnance Survey data @Crown copyright and database right 2014 . 


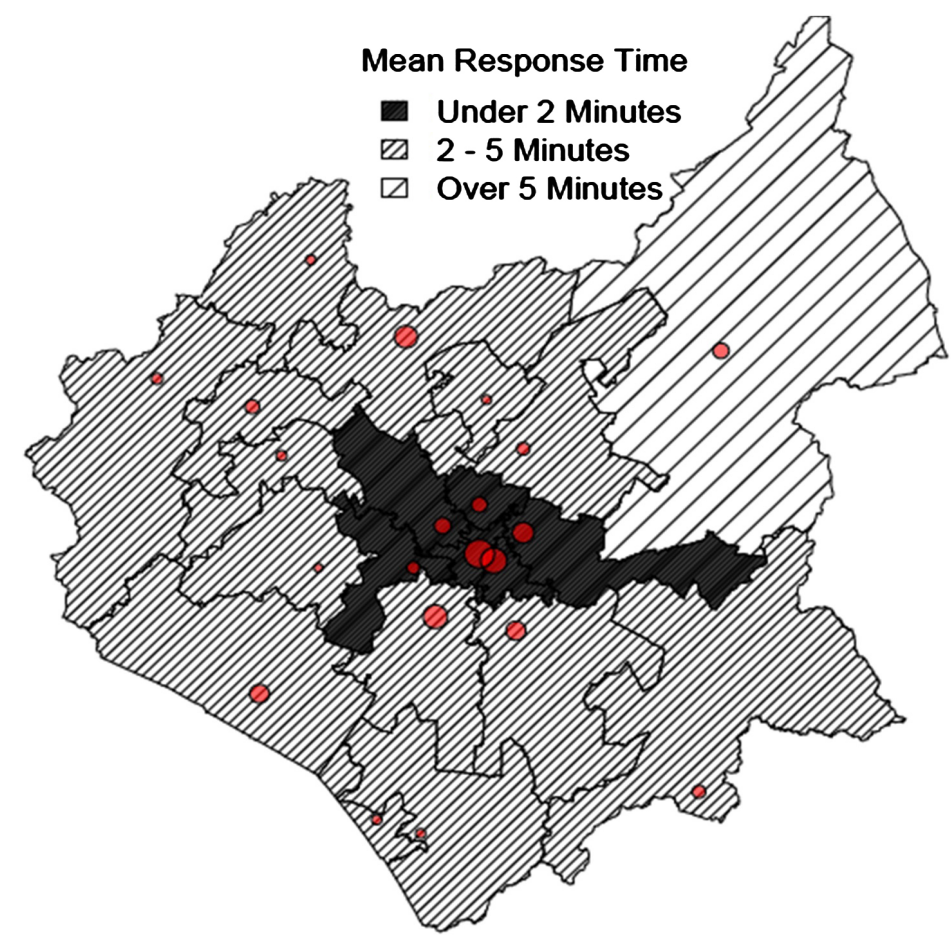

(a)

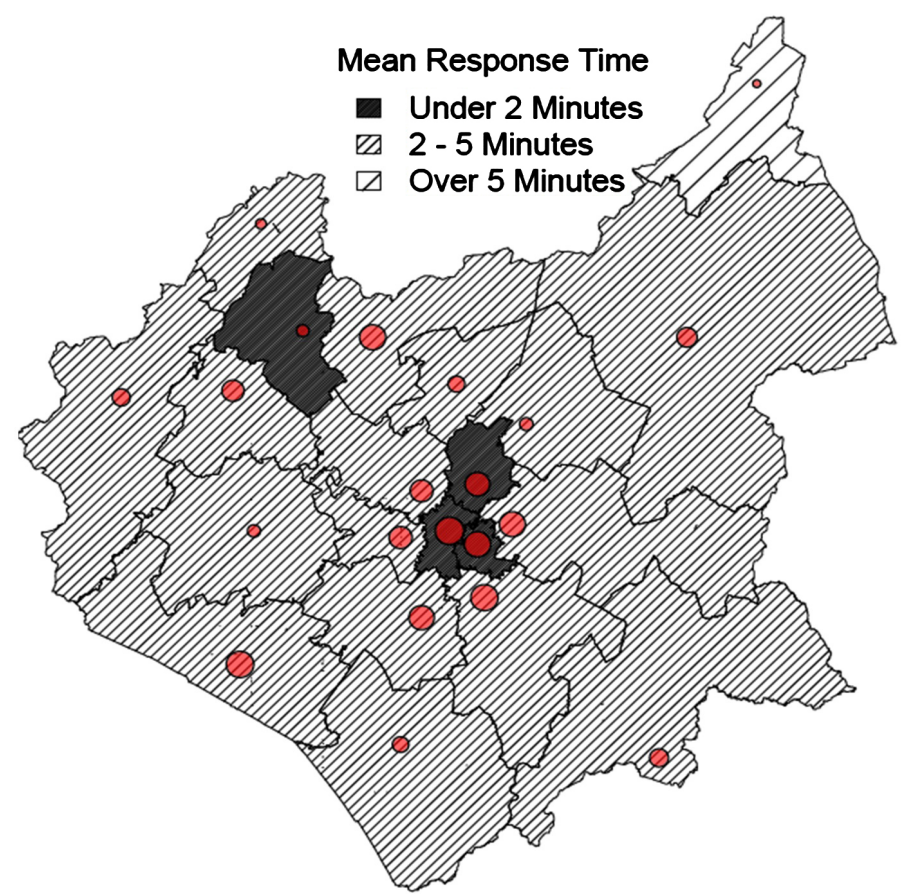

(b)

Figure 3. (a) Map of demand allocation and catchment areas based on the TTW model; (b) Map of demand allocation and catchment areas based on the Residential model. Proportional circles represent selected EMS location, weighted by the maximum demand allocations. The digital boundary file contains National Statistics data $\odot$ Crown copyright and database right (2014) and contains Ordnance Survey data (C) Crown copyright and database (2014). 
Table 2. Demand coverage by models for various response time bands.

\begin{tabular}{cccc}
\hline \multirow{2}{*}{ Model } & \multicolumn{3}{c}{ Mean response time zones (\%) } \\
\cline { 2 - 4 } & Under 2 minutes & $2-5$ minutes & Over 5 minutes \\
\hline TTW & $146,015(44.7)$ & $166,909(51.1)$ & $13,209(4.05)$ \\
Residential & $238,374(24.3)$ & $735,524(75.0)$ & $6430(0.65)$ \\
\hline
\end{tabular}

response time zones. Data in Table 2, may be interpreted as the proportion of demand covered by the models.

The results show that $44.7 \%$ of total non-residential demands are within a mean response time zone of 2 minutes, compared to $24 \%$ by the Residential model. This figure rises to $51.1 \%$, under the 2 - 5 minutes response time zone, but the Residential model covers $75 \%$ demand within the same response time zone. The differences in demand coverage have implications for services location allocation planning decisions in terms of access to EMS when the population is assumed to be static.

Figure 4(a) and Figure 4(b) show differences in the proportions of demand covered within 5 minutes, between the models, by varying the number of EMS sites from 5 to 50, by a set of 5 EMS locations. The graphs depict the number of optimal EMS sites required to achieve a coverage target of $95 \%$. This is represented by the horizontal dotted lines (Figure 4). The results show remarkable differences between the models in terms of the number of optimal EMS needed to achieve the critical target of $95 \%$ demand coverage within 5 minutes. Figure 4(a) shows that the TTW model requires at least 25 locations whereas, the Residential model at least 15 more optimal sites to reach the $95 \%$ coverage target (40 optimal EMS location).

The differences in the number of optimal sites suggest that the Residential model overestimates the number of optimal EMS location required to provide targeted demand coverage of $95 \%$ within 5 minutes from the nearest EMS site. This finding has implications for EMS resource planning policy and staffing considerations during working hours.

Figure 5 shows the result of differences in the mean weighted distance between the models by increasing the number of optimal EMS locations from 5 to 50 , by a set of 5 . The mean weighted distance quantifies the person-distance (minutes) to their nearest EMS location. For instance, optimising EMS locations using the TTW model, is equivalent to minimising the nearest distance, weighted by the number of non-residential or working population. The value of the weighted distance is an indicator of EMS service accessibility. A high value of mean weighted distance suggests poor access to services and a low value suggests otherwise.

The result displayed in Figure 5, shows that increasing the number of EMS sites, results in the reduction of mean weighted distance as expected, in the two models. However, the rate of decline is more in the TTW model, compared to the Residential model. The result indicates that using static residential demand to model locations for service facilities results in higher values of mean 


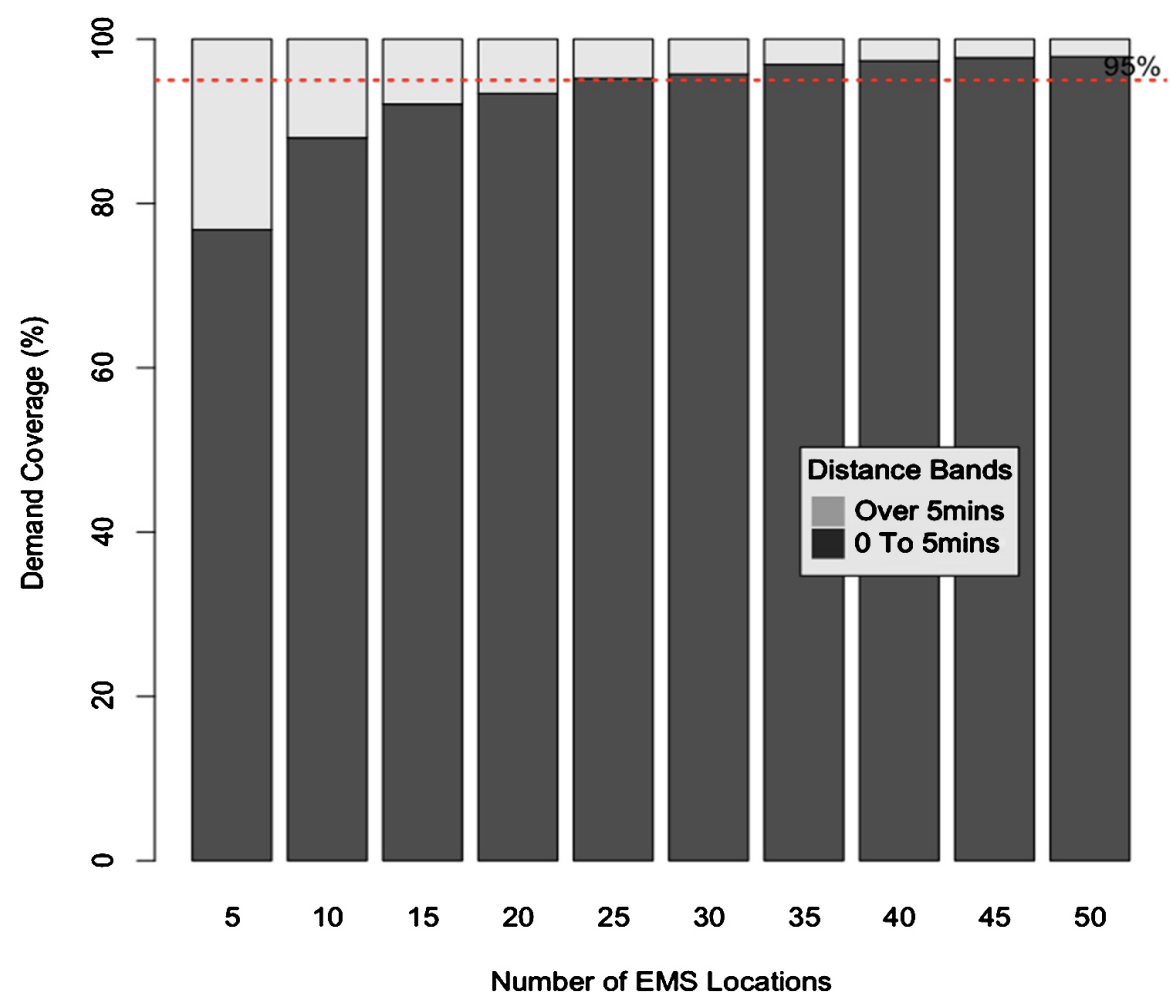

(a)

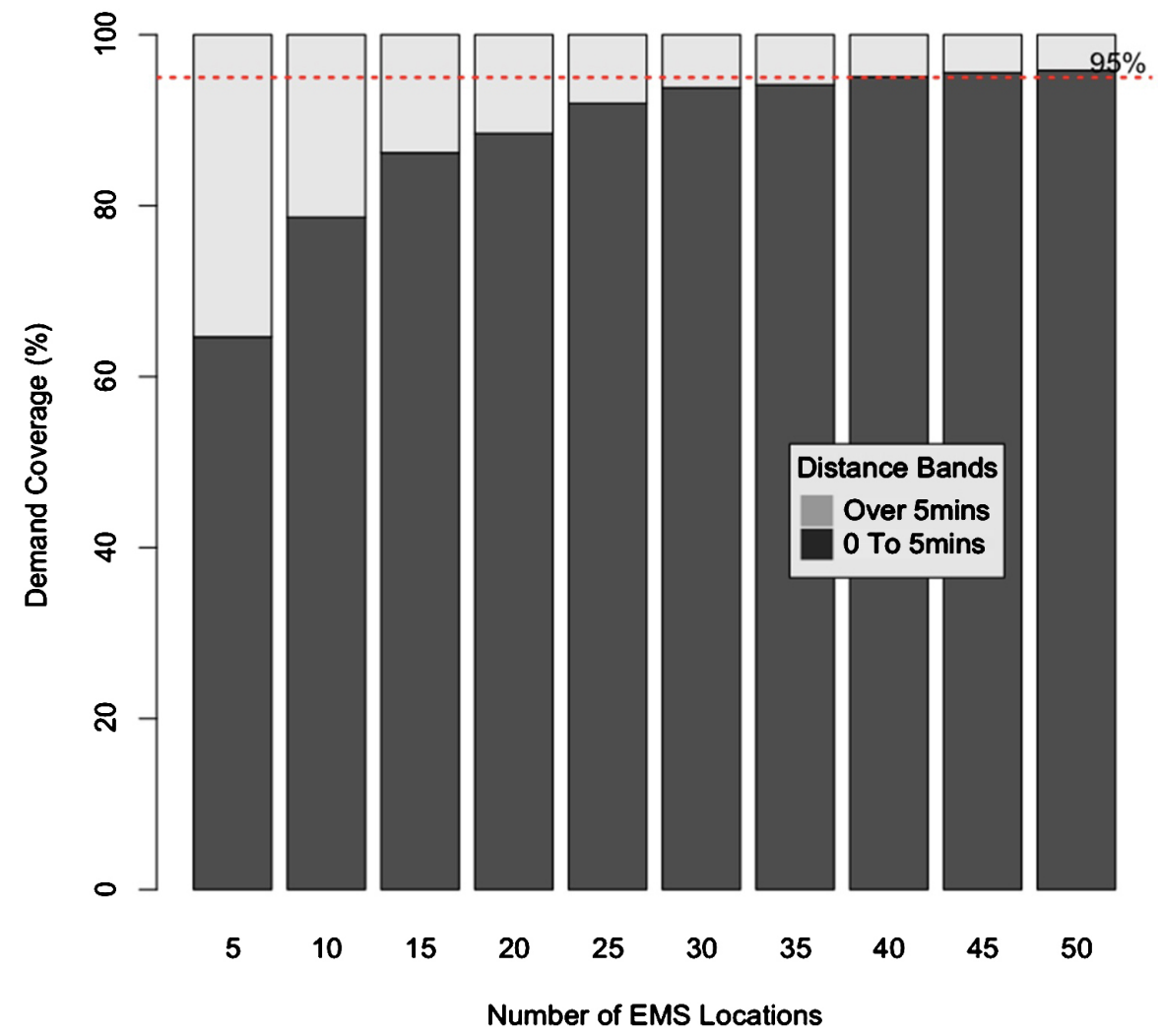

(b)

Figure 4. (a) Proportions of demand covered within 5 minutes based on TTW model; (b) Proportions of demand covered within 5 minutes based on Residential model. 


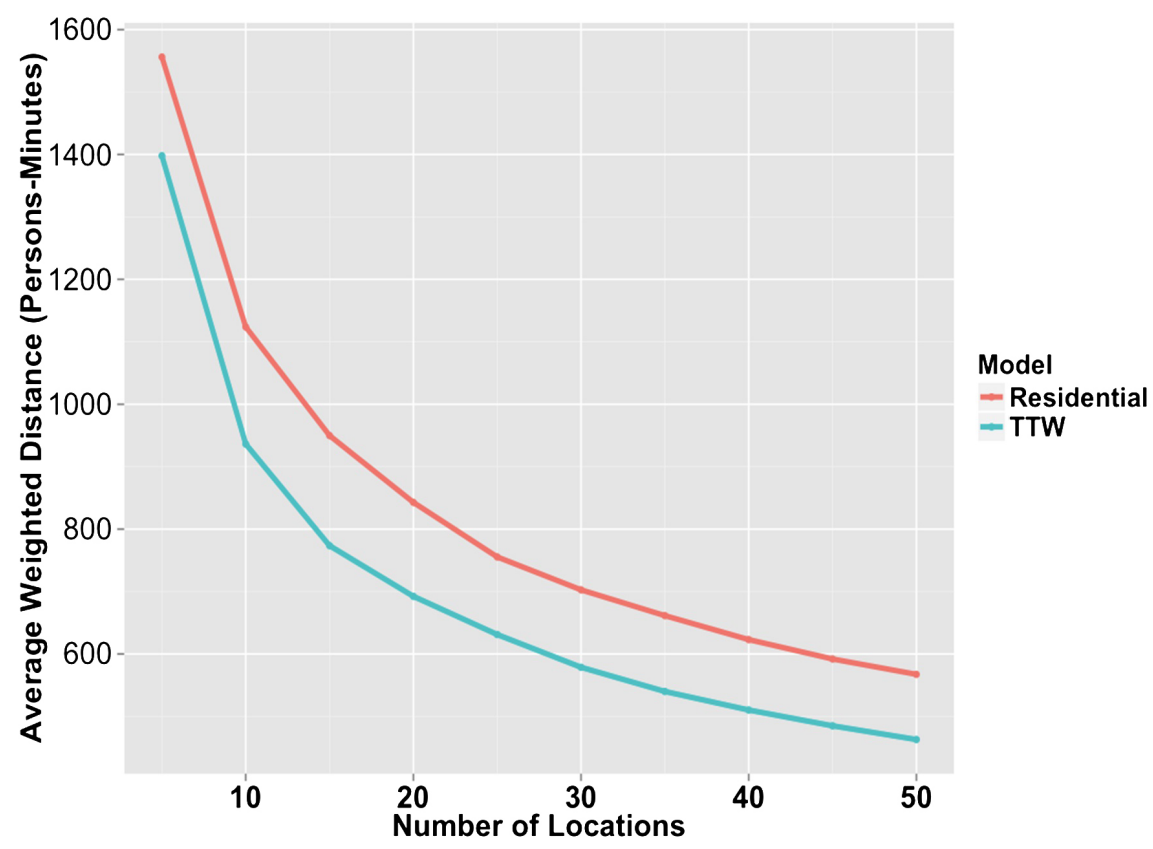

Figure 5. Comparison of mean weighted distance for residential and TTW model.

person-weighted distance. This is indicative that EMS access is overestimated by the Residential model.

\section{Discussions}

The aim of the study was to evaluate the impact of using residential and non-residential demand to plan the location for health services facilities by comparing location-allocation results derived from the TTW and Residential model. The results showed that both models differ in terms of selected optimal location for EMS, proportions of demand allocated to optimal EMS locations, demand coverage and persons-weighted distance to selected EMS site. The results suggest that ignoring non-residential demand, by using a static residential demand in a residential model has implications for location-allocation decision making in terms of where to site service facilities, how demands are allocated to service facilities, planning of service catchments and distribution of service workload across selected optimal locations.

An important consideration in this study was the use of an alternative geography workplace geography (workplace zones) to generate centroid locations for non-residential demand. This enabled the modelling of origin locations for non-residential demand, instead of assuming that both residential and non-residential demand originated from same the locations.

The results of this study have demonstrated the importance of considering non-residential demand when deriving optimal locations for service facilities. The results of this research have shown that integrating non-residential demand into location models and using an appropriate geography to model dynamic demand, has the potential to improve the accuracy of EMS location-allocation 
decision making and management. Although only travel-to-work component of the non-residential population was considered, still, there were differences between the models. The result showed that different optimal EMS locations were identified by the models. This finding suggests that there is the risk of sub-optimally, locating EMS by using only static residential demand or official census estimates. This will have an effect on the efficiency of responses to emergencies, given that effectiveness of EMS is quantified based on their ability to respond to emergencies in a time-efficient manner. The latter depends on where EMS vehicles or resources (ambulances) are prepositioned in relation to the distribution of demand.

The results in Figure 2(a) and Figure 2(b), show that EMS locations are near and within areas of high residential and non-residential population counts. This indicates that locating EMS by considering only static residential demand may result in longer response time in areas with high density of non-residential demand (commercial centres or workplaces). The result can also be used to inform decisions on the dynamic location planning of EMS resources. For instance, set of selected that are identical between the locations can be used to plan permanent sites for location ambulances, whilst sets of different EMS locations can be used to relocate EMS in relation to the dynamic distribution of the population.

Other points of differences between the models, were the proportion of demand allocation (Figure 3), mean response time within catchment areas (Figure 3 ) and proportion of demand covered by EMS (Table 2). The result showed that sizes of demand allocated by the TTW model are fewer compared to the Residential model. The proportion of demand allocated to optimal EMS site may be interpreted as the potential workload per EMS location. The finding suggests that allocating demand based on residential demand significantly overestimates of EMS workload around workplaces. This also has implications for decisions regarding the number of EMS crew that may be allocated to tackle potential emergencies.

The study investigated the implications of the differences between the models on demand coverage by varying the number of EMS locations and imposing a distance constraint of five minutes. The results in Figure 4 revealed that the Residential model requires more EMS locations to meet the target coverage of 95\%, whereas the TTW model covers the same level of demand within only. This finding has an implication for policy formulation on the appropriate number of EMS units to deploy prior to an emergency. For example, a common indicator of EMS performance is to ensure that ambulances get to potential callers within a certain time limit. This means that the number of EMS location maybe overestimated in areas such as schools and commercial centres, where the proportion of non-residential demand is high. Furthermore, an overestimated number of EMS location means that more EMS resources (e.g. Vehicles and personnel) will be deployed in areas with fewer demand.

The study has a number of limitations, for example the absence of real emer- 
gency case data meant that the analysis relied exclusively on travel-to-work and usually resident population counts as proxies of actual EMS demand. This doesn't reflect actual demand for EMS but provided a rationale to compare the two models under the circumstance of potential demand for EMS. Further refinement of the models by integrating other components of non-residential population (e.g. school admission data, retail visits) with appropriate EMS case data can greatly improve the accuracy of model results.

\section{Conclusion}

This article examined the impact of residential and non-residential demand on location-allocation decision making, using EMS location planning in Leicester and Leicestershire as case studies. This was achieved by comparing results generated from a dynamic TTW and a static Residential model. The study has shown that there are important differences between the models. Differences between the models need to be recognised due to their impact on EMS location-allocation decision making and EMS policy formulation. Such differences highlight the significance of incorporating non-residential component of the population into spatially explicit models. It is hoped that the results from this study would increase awareness amongst policy makers and EMS planners on the importance of using dynamic models and integrating non-residential demand to plan the location for EMS.

\section{Conflicts of Interest}

The authors declare no conflicts of interest regarding the publication of this paper.

\section{References}

[1] Eaton, D.J., Sánchez U, H.M.L., Lantigua, R.R. and Morgan, J. (1986) Determining Ambulance Deployment in Santo Domingo, Dominican Republic. Journal of the Operational Research Society, 37, 113-126. https://doi.org/10.1057/jors.1986.21

[2] Badri, M.A., Mortagy, A.K. and Alsayed, C.A. (1998) A Multi-Objective Model for Locating Fire Stations. European Journal of Operational Research, 110, 243-260. https://doi.org/10.1016/S0377-2217(97)00247-6

[3] Flahaut, B., Laurent, M.-A. and Thomas, I. (2002) Locating a Community Recycling Center within a Residential Area: A Belgian Case Study. The Professional Geographer, 54, 67-82. https://doi.org/10.1111/0033-0124.00316

[4] Eiselt, H.A. (2007) Locating Landfills-Optimization vs. Reality. European Journal of Operational Research, 179, 1040-1049. https://doi.org/10.1016/j.ejor.2005.11.039

[5] Borges, O.M. and Antunes, A.P. (2006) School Network Planning in Cape Vert: Maximizing Accessibility vs Minimizing Investment. Joint International Conference on Computing and Decision Making in Civil and Building Engineering, Montreal, 14-16 June 2006, 945-954.

[6] Owen, S.H. and Daskin, M.S. (1998) Strategic Facility Location: A Review. European Journal of Operational Research, 111, 423-447. https://doi.org/10.1016/S0377-2217(98)00186-6 
[7] Hakimi, S.L. (1964) Optimum Locations of Switching Centers and the Absolute Centers and Medians of a Graph. Operations Research, 12, 450-459. https://doi.org/10.1287/opre.12.3.450

[8] Church, R. and ReVelle, C. (1974) The Maximal Covering Location Problem. Papers of the Regional Science Association, 32, 101-118. https://doi.org/10.1007/BF01942293

[9] Toregas, C., et al. (1971) The Location of Emergency Service Facilities. Guidelines for the Practice of Operations Research. Operations Research, 19, 1259-1551.

[10] Rodrigue, J.-P., Comtois, C. and Slack, B. (2013) The Geography of Transport Systems. Routledge, New York.

[11] Bennett, W.D., (1981) A Location-Allocation Approach to Health Care Facility Location: A Study of the Undoctored Population in Lansing, Michigan. Social Science \& Medicine. Part D: Medical Geography, 15, 305-312. https://doi.org/10.1016/0160-8002(81)90006-X

[12] Malczewski, J. and Ogryczak, W. (1990) An Interactive Approach to the Central Facility Location Problem: Locating Pediatric Hospitals in Warsaw. Geographical Analysis, 22, 244-258. https://doi.org/10.1111/j.1538-4632.1990.tb00208.x

[13] Gu, W., Wang, X. and McGregor, S.E., (2010) Optimization of Preventive Health Care Facility Locations. International Journal of Health Geographics, 9, 17. https://doi.org/10.1186/1476-072X-9-17

[14] Mitropoulos, P., et al. (2006) A Biobjective Model for the Locational Planning of Hospitals and Health Centers. Health Care Management Science, 9, 171-179. https://doi.org/10.1007/s10729-006-7664-9

[15] Price, W.L. and Turcotte, M. (1986) Locating a Blood Bank. Interfaces, 16, 17-26. https://doi.org/10.1287/inte.16.5.17

[16] Jacobs, D.A., Silan, M.N. and Clemson, B.A. (1996) An Analysis of Alternative Locations and Service Areas of American Red Cross Blood Facilities. Interfaces, 26, 40-50. https://doi.org/10.1287/inte.26.3.40

[17] Eaton, D.J., et al. (1985) Determining Emergency Medical Service Vehicle Deployment in Austin, Texas. Interfaces, 15, 108. https://doi.org/10.1287/inte.15.1.96

[18] Sasaki, S., Comber, A.J., Suzuki, H. and Brunsdon, C. (2010) Using Genetic Algorithms to Optimise Current and Future Health Planning-The Example of Ambulance Locations. International Journal of Health Geographics, 9, 4. https://doi.org/10.1186/1476-072X-9-4

[19] Khodaparasti, S., et al. (2018) A Multi-Period Location-Allocation Model for Nursing Home Network Planning under Uncertainty. Operations Research for Health Care, 18, 4-15. https://doi.org/10.1016/j.orhc.2018.01.005

[20] Scott, A.J. (1971) Dynamic Location-Allocation Systems: Some Basic Planning Strategies. Environment and Planning A: Economy and Space, 3, 73-82. https://doi.org/10.1068/a030073

[21] Sheppard, E.S. (1974) A Conceptual Framework for Dynamic Location-Allocation Analysis. Environment and Planning A: Economy and Space, 6, 547-564. https://doi.org/10.1068/a060547

[22] Truscott, W.G. (1976) A Note on a Conceptual Framework for Dynamic Location-Allocation Analysis. Environment and Planning A: Economy and Space, 8, 443-446. https://doi.org/10.1068/a080443

[23] Mirchandani, P.B. (1980) Locational Decisions on Stochastic Networks. Geographical Analysis, 12, 172-183. https://doi.org/10.1111/j.1538-4632.1980.tb00026.x 
[24] Schilling, D.A. (1980) Dynamic Location Modeling for Public-Sector Facilities: A Multicriteria Approach. Decision Sciences, 11, 714-724. https://doi.org/10.1111/j.1540-5915.1980.tb01172.x

[25] Drezner, Z. (1995) Dynamic Facility Location: The Progressive P-Median Problem. Location Science, 3, 1-7. https://doi.org/10.1016/0966-8349(95)00003-Z

[26] Sleeter, R. and Wood, N. (2006) Estimating Daytime and Nighttime Population Density for Coastal Communities in Oregon. 44th Urban and Regional Information Systems Association Annual Conference, British Columbia.

[27] Kobayashi, T., Medina, R.M. and Cova, T.J. (2011) Visualizing Diurnal Population Change in Urban Areas for Emergency Management. The Professional Geographer, 63, 113-130. https://doi.org/10.1080/00330124.2010.533565

[28] Tobler, W.R. (1979) Smooth Pycnophylactic Interpolation for Geographical Regions. Journal of the American Statistical Association, 74, 519-530. https://doi.org/10.1080/01621459.1979.10481647

[29] Ahola, T., et al. (2007) A Spatio-Temporal Population Model to Support Risk Assessment and Damage Analysis for Decision-Making. International Journal of Geographical Information Science, 21, 935-953. https://doi.org/10.1080/13658810701349078

[30] Leung, S., Martin, D. and Cockings, S. (2010) Linking UK Public Geospatial Data to Build 24/7 Space-Time Specific Population Surface Models.

[31] Martin, D., Cockings, S. and Leung, S. (2009) Population 24/7: Building Time-Specific Population Grid Models, in European Forum for Geostatistics Conference.

[32] Smith, A., Martin, D. and Cockings, S. (2016) Spatio-Temporal Population Modelling for Enhanced Assessment of Urban Exposure to Flood Risk. Applied Spatial Analysis and Policy, 9, 145-163. https://doi.org/10.1007/s12061-014-9110-6

[33] Guan, X., et al. (2018) Study on Location Allocation of Earthquake Emergency Service Depot Based on Hybrid Multi-Attribute Decision Making. Natural Hazards, 90, 337-348. https://doi.org/10.1007/s11069-017-3051-8

[34] Census Special Workplace Statistics OA: WPZ (2011) [Location of Usual Residence and Place of Work (Excluding Those with Quasi-Workplaces)]-WF01AEW-Open 2011 SWS OA: WPZ [Location of Usual Residence and Place of Work (Excluding Those with Quasi-Workplaces)]_WF01AEW—Open.

[35] Census Special Workplace Statistics OA: OA (2011) [Location of Usual Residence and Place of Work]-WF01BEW-Open.

[36] ReVelle, C.S. and Swain, R.W. (1970) Central Facilities Location. Geographical Analysis, 2, 30-42. https://doi.org/10.1111/j.1538-4632.1970.tb00142.x

[37] Reese, J. (2006) Solution Methods for the P-Median Problem: An Annotated Bibliography. Networks, 48, 125-142. https://doi.org/10.1002/net.20128

[38] Teitz, M.B. and Bart, P. (1968) Heuristic Methods for Estimating the Generalized Vertex Median of a Weighted Graph. Operations Research, 16, 955-961. https://doi.org/10.1287/opre.16.5.955

[39] Chiyoshi, F. and Galvao, R.D. (2000) A Statistical Analysis of Simulated Annealing Applied to the P-Median Problem. Annals of Operations Research, 96, 61-74.

[40] Glover, F. (1990) Tabu Search: A Tutorial. Interfaces, 20, 74-94. https://doi.org/10.1287/inte.20.4.74

[41] Domínguez, E. and Muñoz, J. (2008) A Neural Model for the P-Median Problem. Computers \& Operations Research, 35, 404-416. https://doi.org/10.1016/j.cor.2006.03.005 
[42] Correa, E., et al. (2004) A Genetic Algorithm for Solving a Capacitated P-Median Problem. Numerical Algorithms, 35, 373-388.

https://doi.org/10.1023/B:NUMA.0000021767.42899.31

[43] Comber, A.J., et al. (2011) A Modified Grouping Genetic Algorithm to Select Ambulance Site Locations. International Journal of Geographical Information Science, 25, 807-823. https://doi.org/10.1080/13658816.2010.501334

[44] Comber, A., et al. (2008) Using a GIS-Based Network Analysis and Optimisation Routines to Evaluate Service Provision: A Case Study of the UK Post Office. Applied Spatial Analysis and Policy, 2, 47-64. https://doi.org/10.1007/s12061-008-9018-0 